\title{
Exploring the Policy of Early Childhood Education in the Development of Common Good based on Complex System Theory
}

\author{
Byung-Man Kim, Professor, Dept. of Early childhood education, Kyungnam University, Changwon, 5 \\ 1767, Republic of Korea \\ *Su-Jeong Jeong, Research Professor, Creativity \& Personality Laboratory, Tongmyong University, Bus \\ an, 48570, Republic of Korea, jsjs@tu.ac.kr \\ ${ }^{*}$ Corresponding Author
}

\begin{abstract}
Through the early childhood education policy plan for promoting the common good based on the complex system theory, the government intends to present the early childhood education policy plan based on the principle of the common line in which everyone can coex ist and contribute to the rational policy decision-making process. Big data analysis using Text om, two FGD analysis for four experts in early childhood education and 20 AHP analysis we re conducted for 16 experts in early childhood education field, and six FGI and 4 experts in early childhood education policy, to explore policies for early childhood education based on c omplex system theory. Top factors such as interest group factors, governance factors, and soc ial factors were presented for the promotion of joint election and early childhood education policies. As a result of a detailed review of the comprehensive weighting of the early childho od education policy measures to promote the common good, it was found that among the 1 5 subtexts, the highest weighting from the expert panel was the establishment of a cooperati ve network among stakeholders related to early childhood education policies. The results of $t$ he study provide meaningful implications that the first hierarchy, the "group of stakeholders" factor, can be interpreted as having the highest weighting in the analysis of the importance of the top factors.
\end{abstract}

Keywords: Early childhood education policy, Common good, Complex system theory, Bottom-up policy formulation, Analytic hierarchy process, Big data analysis.

Received: 07.12.2020 Accepted: 13.01.2021 Published: 03.02.2021

\section{INTRODUCTION}

For a happy society centered on early childhoods, good quality childcare and childcare policies should be developed, along with administrative and financial support. In the world, policy changes centering on early childhood education and childcare are actively being carried out, and the size and subject of the business are also gradually expanding and diversifying. As the awareness of the importance of early childhood / toddlerhood increases, support for early childhood and toddlerhood will be the most definitive preparation for the future that can be shown in the current society with low birth and aging issues. Early childhood education policy is a criterion for diagnosing a country's national power and capabilities, and is an important criterion that closely links individual development, growth, and the future of the people. This early childhood education policy has created a national consensus on strengthening public character as the social demand and consensus that the state and family should jointly take responsibility for raising children[1]. Three concepts of citizenship, public welfare, and communication have been presented as key elements of public interest[2]. True publicness is established only when the process conditions of communication, in which opinions are freely exchanged and judged through the restoration of citizens' identity and the pursuit and procedure of public welfare, are met. Emphasizing that a member should be the main body and not only seek a large number of interests against private interests, but should be based on the rationality and openness of the process in its arguments, consensus and practice. Koo (2015) compares the nature of public nature with OECD countries and claims that Korea's public nature has an exclusive liberal public character[3]. He criticizes that the public nature discourse in our country approaches the public nature as a normative and institutional principle of the realm of management and control by the state, and relies on the single-track logic that if the nation's public domain is encroached by market logic, it loses its public character. Lee (2017) suggests that in order to overcome the distortion of public character, it is necessary to reconstruct 
public character in a participatory and inclusive way that will consolidate the members' participation base[4]. Lee argues that Korea's early childhood education policy is at a time when it should shift from a public nature that aims for a universal and public domain to a common good. Emphasizing collective interests in accordance with the principle of public nature, which is for the benefit of the majority, emphasizes that the dignity and respect of the human individual and the value of the common good of human life can be overlooked.

The recent characteristics of the government's early childhood education policy are that it takes a universal welfare position under the pretext of national responsibility. Although the public nature system is expanding by including all early childhoods in early childhood education policies, it recognizes the importance of early childhood education on a universal and demographic level rather than on a level that recognizes diversity. Kim (2018) argued that the direction of early childhood education policy should be shifted from a public-oriented perspective that emphasizes the universal and public domain of the government to a common-line perspective based on the view of the common line that preserves the safety, happiness, etc. of the living community and pursues the right direction of public policy[1].

Early childhood education policies are influenced by environmental factors because they are formed in various environments such as politics, economy, population, ideology and values of society. In order to increase the participation of various groups and members in early childhood education policies, the scope and content should also be directly and systematically reflected in the theories formed by the specific results of the research accumulated so far, methodological actual and universal social values recognized through field experience and research[5]. In the process of establishing early childhood education policies, various fields and groups, including research institutes, scholars, interest groups, media outlets and the public, should directly or indirectly participate in the process of establishing policies for children. Anyone who wants to be a policy-maker, a policy-maker, or a policy-maker who wants to influence a policy-maker will inevitably see it as a country[6]. For those who decide on early childhood education policies to work successfully, they must explain their plans, go through the process of public review, and persuade others to support their ideas. At the same time, one must develop one's thoughts and views between checks and balances. If the policy-maker fails to persuade others, the plan established cannot be implemented.

Hargreaves and Shirley (2009) use the concept of 'The Fourth Way' to claim that the era of pursuing democratic and professional changes that are central to change and reform has come, and are proposing the direction we should pursue in the future[7]. As such, innovation, inspiration, responsibility and sustainability are required on the fourth road, and all the state and its members, including members, should be at the center of change and reform. Promotion of co-line early childhood education policy based on complex system theory must go through the process of explaining their plans, going through the process of public review, and persuading others to support their ideas in order to successfully achieve their goals. At the same time, one must develop one's thoughts and views between checks and balances[6].

In this study, in proposing measures to promote joint selection of early childhood education policies based on complexity theory, the target was extended to the areas of big data early childhood educationrelated members rather than relying solely on a group of experts in policymaking, and it was valuable in establishing a bottom-up policy to gather opinions from members in the process of policymaking. Consultation and agreement based on in-depth understanding of the establishment of common good promotion early childhood education policy based on complex system theory is requested. If we gather our minds and wills together, we believe that all members will be happy and that a high-quality early childhood education policy that contributes to the development of Korea will be implemented.

Despite the accumulation of micro-study on early childhood education policies, it is pointed out that the existing research on early childhood education policy does not properly help the actual phenomenon of early childhood education. This is because existing studies have viewed early childhood education policy as mechanical complexity and presented fragmentary research results focusing only on one characteristic by dividing the main factors causing the problem into demographic, economic, and cultural factors. In other words, it is due to the lack of a proper understanding of the nature of early childhood education policy, a dynamic ecological complexity, by seeking causal linearity. In particular, the early childhood education policy approach to the low birth rate problem, which is a problem of the times, and the corruption of private kindergartens is representative. Despite the accumulation of micro-research on low birth rates, it has been pointed out that existing low birth rates have not been properly analyzed. This is due to the fact that existing studies have failed to understand the low birth rate, which is a dynamic ecological complexity phenomenon, by viewing it as mechanical complexity, and by focusing on one characteristic by dividing the main factors causing it into demographic, economic, and cultural factors, to present fragmentary research results or to find causal linearity.

Most studies are done by analyzing women or households from different backgrounds in the same group, and few studies are found analyzing multilayered and complex phenomena of low birth rates. In 
particular, the factors influencing low birth rates were analysed, focusing on maternity activities at certain times or those already completed in the past, which had a relatively low effectiveness in predicting future actions due to continuous changes in social and cultural backgrounds[8-10].

In order to explore early childhood education policy measures for a healthy future society as discussed above, it is argued that the direction of seeking common good in the public sector, expanding from the area of experts to the area of members, and understanding dynamic and ecological complexity in causal linearity. Therefore, this study aims to empirically analyze the members' perceptions and needs through FGI, FGD, and layering analysis methods to explore common good promotion early childhood education policy measures based on complex system theory. In conclusion, through this study, we are going to reveal the complexity of early childhood education policy phenomenon and suggest the direction of reform as internal and external factors by presenting measures for early childhood education policy to promote joint election. Based on the theory of complex systems, we believe that we will be able to present early childhood education policy measures based on the principle of co-prosperity and contribute to the rational policy decision-making process.

\section{Materials and methods}

\subsection{Big Data Analysis}

This study seeks to look at the perspective of complex system theory in order to explore common good promotion early childhood education policy measures. Until now, most of the studies related to early childhood education policy have been categorized as institutional and economic factors to focus on one or two factors, or to identify the causes of early childhood education policies as fragmentary and linear causal relationships. However, in this study, we would like to note the complexity and dynamics of the Early Childhood Education Finance Policy phenomenon[11]. We want to look at the early childhood education policy phenomenon as an ecological complexity phenomenon, and to find a voluntary and macro order hidden in the phenomenon from a complex system perspective, a system that shows creativity. To this end, we want to utilize big data analysis based on complexity theory. In this study, Textom, a big data analysis solution developed by the IMC, was used for data collection and data processing.

\subsection{FGI( focus group interview) and FGD(focus group discussion)}

FGI and FGD are planned to be conducted for 20 experts(16 experts in early childhood education field, 4 experts in early childhood education policy) in order to analyze issues related to the promotion of joint selection of early childhood education policies. In the case of on-site experts in early childhood education policy, a total of six FGI sessions were conducted, two separate FGI sessions for each of the two sessions, including a scholarship officer in charge of early childhood education, the heads of state and public kindergartens, and the heads of state and public kindergartens, and the teachers of the private kindergartens. Based on this, FGD was conducted twice for a group of experts from the academia in early childhood education policy.

Unlike FGI, FGD is a more open research method than FGI by allowing debaters to express their opinions independently of each other, not by answering questions set by one-sided interviews. The qualitative study of the FGD approach is interpreted by participants as active collaborators producing knowledge[12]. Processing and analysis of FGI and FGD were analyzed using the constant comparison method of the grounded theory based on the transcription data recorded in the interview and the site notes prepared in the discussion process. The contents of the interview were analyzed through an open coding process in which researchers read the interview content and categorize the data according to the questions and topic coding process in which the data is categorized according to the questions[13].

The analysis category secured the reliability and validity of the research by analyzing data through continuous comparison methods and cross-checking procedures in consultation with three experts in early childhood education who have experience in carrying out qualitative research. In addition, opinions that were consistent or inconsistent at the level of organizing the data were classified and organised through repeated comment statements and coordination by three early childhood education experts, and additional questions were asked via phone and e-mail after the Focus Group interview if there were any questions about the results or further discussion needed.

\subsection{Analytic Hierarchy Process}

In this study, the priority of the common good promotion early childhood education policy plan was derived using the Analytic Hierarchy Process (AHP technique). In this study, a panel of 20 experts in early childhood education was organized to derive the priority of policies for early childhood education that promote joint selection through layering analysis. Participants in the layering analysis consisted of 10 experts from the Early Childhood Education Policy academia and 10 experts from the Early Childhood Education Policy field. 
The layering analysis method, in which expert panels participated, calculated the weights by adding the ratings of a number of decision makers. Therefore, in accordance with the method of prior research[14-15] using the layering analysis method, the two contrast bridge values of each evaluator were calculated item by item and derived as the value of the input matrix. For weight analysis, the response data of the Delphi panel were analyzed with Expert Choice 11.5 program according to the procedure of the layering analysis method described earlier. The geometric mean of the entire panels for each double contrast item was calculated and the input matrix was created to derive weights, consistency indices, and consistency ratios for each pair item. This study confirmed the consistency of the data in accordance with the suggestion of Saaty[16], who said that the double contrast matrix was consistent only when the consistency ratio was calculated within 0.1 .

\section{Results}

3.1 Frequency of keywords related to integration early childhood education and childcare

The frequency analysis of keywords related to early childhood education policy showed that kindergartens $(2,027)$ had the highest frequency, followed by private kindergartens $(1,345)$, education offices (1,300), financial support (1,052), operation (678), early childhoods (644), parents (549), budget (480), government (446), and early childhood education law (432).

Keywords located in the top 100 among keywords related to early childhood education policies showed group factors of stakeholders (private kindergartens, parents, the government, and the National Assembly). Next came the policy and administrative factors (financial support, budget, first-time school, Nuri curriculum, audit, public education, subsidies, kindergarten operation committee, etc.) and the relevant statutes (such as the early childhood education act, private school act, school lunch act, etc.) and the social response factors (publicity, transparency, autonomy, professionalism, private property rights, teacher treatment, kindergarten 3 laws, etc.), private educational facilities, non-profit educational institutions, support institutions, support, support, and schools, and schools.

\subsection{Policy measures for early childhood education to promote common good}

In this study, six FGIs and two FGDs were conducted to explore ways to promote joint election. Various and in-depth opinions were presented to the experts who participated based on the results of big data analysis on early childhood education policies. In summary, the following common good promotion early childhood education policy measures were proposed.

First, top factors such as interest group factors, governance factors, and social factors were presented for joint election promotion early childhood education policies. Specifically, the group of stakeholders proposed agreements between relevant stakeholders of the Ministry of Education and the Ministry of Health and Welfare, agreements between relevant stakeholders in the field of early childhood education and childcare, agreements between relevant stakeholders in the fields of national and public kindergartens and private kindergartens, establishment of a cooperative network between stakeholders related to early childhood education policies, and establishment of organizations for the consensus of stakeholders in early childhood education policies.

Next, governance factors suggested that the government, education offices and local governments establish a cooperative system for early childhood education policies, equitable support for early childhood education finance for those subject to early childhood education, expansion of state-run kindergartens in a way that public and private kindergartens coexist, proposals for early childhood education policies in response to low birth rates, and enhanced government policy accountability for early childhood education policies.

Finally, social factors suggested strengthening the social public nature of early childhood education policy, ensuring social transparency of early childhood education policy, forming a social consensus on the importance and necessity of early childhood education, understanding the responsibilities and roles of social members in early childhood education policy, and establishing a social consensus system for early childhood education policy.

\subsection{Priority of early childhood education policy to promote common good}

The questionnaire for calculating the weight of the relative importance analysis of the Early Childhood Education Policy Measures for the Promotion of common good consisted of two phases, three top factors and 15 sub-content. A pair-wise comparison was developed to derive the relative weight of the higher factors, lower contents, on the hierarchy of the proposed common good promotion early childhood education policy measures in this study. The two-way questionnaire provided a comparative comparison of the importance between the assessment factors to be determined on a 9-point scale. A panel of 20 experts was organized for the twin bridge survey to derive the weight of the assessment criteria. The first calculation of the consistency ratio (CR) for individual panel-specific ratings showed that the consistency ratio of 15 panel responses among 20 panel members was higher than 0.1 . Therefore, a second survey 
was conducted to re-evaluate panels with high consistency ratios. The analysis of the first and second surveys showed that the response results of a 20-person panel with an average consistency ratio below 0.1 were adopted for the final analysis. The weighting results for the higher factors are shown in Table 1 .

Table1 Higher factor simple weighting

\begin{tabular}{|l|l|l|l|}
\hline Top factor & $\begin{array}{l}\text { Higher } \\
\text { weighting factor }\end{array}$ & PCT(\%) & Priority \\
\hline $\begin{array}{l}\text { 1. Interested Group } \\
\text { Factor }\end{array}$ & .44 & 44.1 & 1 \\
\hline 2. Governance Factors & .26 & 25.8 & 3 \\
\hline 3. Social factors & .30 & 30.1 & 2 \\
\hline Sum of weights & 1.00 & 100.0 & \\
\hline
\end{tabular}

As shown in Table 1, a detailed study of the higher categories of simple weights in the early childhood education policy measures for promoting joint election showed that $44.1 \%$ of 'group factors of interest', $30.1 \%$ of 'social factors' and $25.8 \%$ of 'factors of governance'. This provides implications for the joint election promotion early childhood education policy plan, as it determines the importance of the three top factors in order of stakeholder group factor $>$ social factor $>$ governance.

The following is the composition of the lower hierarchy of the policy measures for early childhood education to promote joint election. Among the three perspectives, which are the first hierarchy, there are a total of 15 content, five from the top factors of the interest-related group factor, five from the Governance factor, and five from the Social factor. The simple weights and the overall weights and priorities according to the sub-categories of the Early Childhood Education Policy for the Promotion of common good are shown in Table 2.

Table1 Higher factor simple weighting

\begin{tabular}{|c|c|c|c|c|c|}
\hline Top factor & $\begin{array}{l}\text { Higher } \\
\text { factor } \\
\text { weighting }\end{array}$ & subtext & $\begin{array}{l}\text { subtext } \\
\text { Simple } \\
\text { Weight }\end{array}$ & $\begin{array}{l}\text { subtext } \\
\text { aggregate } \\
\text { weight }\end{array}$ & Priority \\
\hline \multirow{5}{*}{$\begin{array}{l}\text { 1. Interested } \\
\text { Group } \\
\text { Factor }\end{array}$} & \multirow{5}{*}{.441} & $\begin{array}{l}\text { 1-1. Agreement between } \\
\text { relevant stakeholders of the } \\
\text { Ministry of Education and the } \\
\text { Ministry of Health and Welfare. }\end{array}$ & .168 & .074 & 5 \\
\hline & & $\begin{array}{l}\text { 1-2. Agreements among } \\
\text { relevant stakeholders in early } \\
\text { childhood education and child } \\
\text { care }\end{array}$ & .229 & .101 & 2 \\
\hline & & $\begin{array}{l}\text { 1-3. Agreements between } \\
\text { relevant stakeholders in the } \\
\text { field of public and private } \\
\text { kindergartens }\end{array}$ & .133 & .059 & 9 \\
\hline & & $\begin{array}{l}\text { 1-4. Establishing a cooperative } \\
\text { network among stakeholders } \\
\text { related to early childhood } \\
\text { education policies }\end{array}$ & .264 & .116 & 1 \\
\hline & & $\begin{array}{l}\text { 1-5. Establishment of an } \\
\text { Organization for Agreements } \\
\text { of Interested Officials in Early } \\
\text { Childhood Education Policy }\end{array}$ & .206 & .091 & 4 \\
\hline $\begin{array}{l}2 . \\
\text { Governance } \\
\text { Factors }\end{array}$ & .258 & $\begin{array}{l}2-1 . \text { The government, } \\
\text { education offices, and local } \\
\text { governments establish a } \\
\text { cooperative system for early } \\
\text { childhood education policies. }\end{array}$ & .227 & .059 & 9 \\
\hline
\end{tabular}




\begin{tabular}{|c|c|c|c|c|c|}
\hline & & $\begin{array}{l}\text { 2-2. Affordable support for the } \\
\text { financial support of early } \\
\text { childhood education for those } \\
\text { subject to early childhood } \\
\text { education. }\end{array}$ & .235 & .061 & 8 \\
\hline & & $\begin{array}{l}\text { 2-3 Expansion of public and } \\
\text { public kindergartens in a way } \\
\text { that public and private } \\
\text { kindergartens co- }\end{array}$ & .218 & .056 & 11 \\
\hline & & $\begin{array}{l}\text { 2-4. Proposal of Early } \\
\text { Childhood Education Policy in } \\
\text { Response to Low Birth Rate }\end{array}$ & .172 & .044 & 12 \\
\hline & & $\begin{array}{l}2-5 . \quad \text { Strengthening the } \\
\text { Government's Policy } \\
\text { Responsibility for Early } \\
\text { Childhood Education Policy }\end{array}$ & .148 & .038 & 13 \\
\hline \multirow{5}{*}{$\begin{array}{l}\text { 3. Social } \\
\text { factors }\end{array}$} & \multirow{5}{*}{.301} & $\begin{array}{l}\text { 3-1. Strengthening the Social } \\
\text { Publicity of Early Childhood } \\
\text { Education Policy }\end{array}$ & .124 & .037 & 15 \\
\hline & & $\begin{array}{l}\text { 3-2. Guaranteeing Social } \\
\text { Transparency in Early } \\
\text { Childhood Education Policy }\end{array}$ & .125 & .038 & 13 \\
\hline & & $\begin{array}{l}\text { 3-3. Establishing a Social } \\
\text { Consensus on the Importance } \\
\text { and Necessity of Early } \\
\text { Childhood Education }\end{array}$ & .206 & .062 & 7 \\
\hline & & $\begin{array}{l}\text { 3-4. Understanding the } \\
\text { responsibilities and roles of } \\
\text { social members in early } \\
\text { childhood education policies }\end{array}$ & .240 & .072 & 6 \\
\hline & & $\begin{array}{l}\text { 3-5. Establishing a Social } \\
\text { Consensus System for Early } \\
\text { Childhood Education Policy }\end{array}$ & .305 & .092 & 3 \\
\hline $\begin{array}{ll}\begin{array}{l}\text { Sum } \\
\text { weights }\end{array} & \text { of } \\
\end{array}$ & 1.000 & & 1.000 & & \\
\hline
\end{tabular}

As shown in Table 2, the comprehensive weighting of early childhood education policy measures for promoting joint election was examined in detail, and among the 15 sub-contents, the highest weighting from the expert panel was '1-4. Establishing a cooperative network among stakeholders related to early childhood education policies'(.116). Next, the order of priority was '1-2. Agreements among relevant stakeholders in early childhood education and child care'(.101), '3-5. Establishing a social consensus system for early childhood education policy'(.102), '1-5. Establishment of an organization for agreements of interested officials in early childhood education policy'(.090), and 'Agreement between relevant stakeholders of the Ministry of Education and the Ministry of Health and Welfare'(.074).

\section{Conclusions}

The conclusions based on the results of this study are as follows. First, as a result of frequency analysis of keywords related to early childhood education policy, the top 100 keywords related to early childhood education policy showed a group of stakeholders. Next, policy and administrative factors were presented, and relevant statutes and social response factors were presented. Based on these results, the understanding of early childhood education policies was derived by dividing them into stakeholders, governance and social factors.

Second, top factors such as interest group factors, governance factors, and social factors were presented for joint election promotion early childhood education policies. Specifically, the group of stakeholders proposed agreements between relevant stakeholders of the Ministry of Education and the Ministry of Health and Welfare, agreements between relevant stakeholders in the field of early childhood education and childcare, agreements between relevant stakeholders in the fields of national and public 
kindergartens and private kindergartens, establishment of a cooperative network between stakeholders related to early childhood education policies, and establishment of organizations for the consensus of stakeholders in early childhood education policies. Next, governance factors suggested that the government, education offices and local governments establish a cooperative system for early childhood education policies, equitable support for early childhood education finance for those subject to early childhood education, expansion of state-run kindergartens in a way that public and private kindergartens coexist, proposals for early childhood education policies in response to low birth rates, and enhanced government policy accountability for early childhood education policies. Finally, social factors suggested strengthening the social public nature of early childhood education policy, ensuring social transparency of early childhood education policy, forming a social consensus on the importance and necessity of early childhood education, understanding the responsibilities and roles of social members in early childhood education policy, and establishing a social consensus system for early childhood education policy.

Third, the comprehensive weighting of the early childhood education policy measures to promote the joint election was examined in detail, and among the 15 subtexts, the highest weighting from the panel of experts was 'Establishing a cooperative network among stakeholders related to early childhood education policy'. Next, the order of priority was 'agreement between relevant stakeholders in the field of early childhood education and childcare', 'establishing a social consensus system for early childhood education policy', 'establishing a group for the agreement of early childhood education policy stakeholders', and 'agreement between relevant stakeholders in the Ministry of Education and the Ministry of Health and Welfare'. These findings provide meaningful implications that the 'group of interested parties' factor can be interpreted as having the highest weighting in the first hierarchy, the analysis of the importance of the higher factors.

The implications of this study through the above conclusions are as follows: First, through this study, we were able to empirically analyze the members' perceptions and demands by proposing policies for early childhood education to promote joint election, and we expect that the measures for early childhood education policy to be understood in a timely manner. Through this, we believe that we will be able to present early childhood education policy measures based on the principle of a common good that everyone can coexist and contribute to the rational policy decision-making process. It is also expected that social and academic discourse on the need for follow-up research can be expanded and formed through research on early childhood education policy measures, which are the main subjects of interest in the times and society.

Second, the findings are expected to open a new chapter in the field of early childhood education policy. Specifically, it is judged that the members will present a roadmap on how to solve problems and cope with them through the recognition and demand of the members for the promotion of the joint election, analysis of major issues of the joint election promotion policy, and establishment of policy measures for the promotion of the joint election. It is expected that this will pave the way for future national policy research.

Third, through this study, we will be able to secure various perspectives and perspectives in the field of national policy on early childhood education policies for promoting joint election, and will be able to have critical thinking about the current top-down policy implementation system. In addition, it is expected to serve as a medium to supplement the current policy implementation system and system, and to have high implications for the bottom-up policy implementation.

In conclusion, it is judged that this study will serve as an opportunity to reflect the opinions and needs of the people in establishing and implementing early childhood education policies through the exploration of common good promotion early childhood education policy measures. In addition, it is judged that the government will present specific policies that can resolve the policy issues of early childhood education in Korea more smoothly from the perspective of the common election, providing timely and social solutions to the measures to promote the joint election of early childhood education policies.

\section{Acknowledgements}

This work was supported by the Ministry of Education of the Republic of Korea and the National Research Foundation of Korea(NRF-2019S1A5A8035572).

\section{References}

[1] Kim BM. Development of Evaluation Scale for Early Childhood Education Policy for Parents. Journal of Educational Innovation Research. 2018;28(4):1-26. DOI:10.21024/pnuedi.28.4.201812.1

[2] Cho HS. What is publicity? Seoul: chaeksesang;2009.

[3] Koo HR. Does Publicness Reduce Risks? : Examined Across OECD Countries. Korea Social Policy Review. 2015;22(1):19-47. DOI:10.17000/kspr.22.1.201503.19 
[4] Lee KH. A critical review of the current childcare and education policies: transition from public interest to common good. The Journal of Eco Early Childhood Education \& Care. 2017;16(1):237256.

[5] Kim BM. The development direction of the evaluation scale for early childhood education policy, based on the neo-liberal critical. The Journal of Eco Early Childhood Education \& Care. 2015;14(2):111136.

[6] Diane R. The Death and Life of the Great American School System: How Testing and Choice Are Undermining Education. New York: Diane Ravitch; 2010.

[7] Hargreaves A, Shirley D. The persistence of presentism. Teachers College Record. 2009;111(1):25052534.

[8] Kwak YC. The Effects of Economic Factors on Household Formation: Focused on Relative Income and Housing Expenses [Doctoral dissertation]. Seoul National University; 2017.

[9] Kim CS. Parity Specific Approach to the Plan of Having an Additional Child. Korea Journal of Population Studies. 2007;30(2):97-116.

[10] Min HJ, Kim EJ. The Timing of Births among Korean Women: Parity Differences in Childbirths. Korean Journal of Sociology. 2011;45(4):198-222.

[11] Davis B, Sumara D, Luce-kapler R. Engaging Minds: Cultures of Education and practices of Teaching Third Edition. NEW YORK \& LONDON: Routledge; 2016.

[12] Alex L, Fjellman WA, Lundman B, Christianson M, Hammarström A. Beyond a Dichotomous View of the Concepts of 'Sex' and 'Gender' Focus Group Discussions among Gender Researchers at a Medical Faculty. PLoS ONE. 2012;7(11):e50275. https://doi.org/10.1371/journal.pone.0050275

[13] Creswell J W. Qualitative Inquiry and Research Design: Choosing Among Five Approaches. California: SAGE Publications; 2007.

[14] Kim KH. Development of BSC performance evaluation model for university lifelong education center [Doctoral dissertation]. Dong-Eui University; 2014.

[15] Kim BM. Development of early childhood education policy evaluation criteria [Doctoral dissertation]. Pusan National University; 2014.

[16] Saaty TL. Decision making for leaders: The Analytic Hierarchy Process for Decisions in a Complex World. Pennsylvania: RWS Publications; 1995. 